\title{
Cost Impact of Prospective HLA-B*5701-screening Prior to Abacavir/Lamivudine Fixed Dose Combination Use in Germany
}

\author{
E. Wolf ${ }^{1}$, M. Blankenburg', J. R. Bogner ${ }^{3}$, W. Becker ${ }^{4}$ D. Gorriahn ${ }^{5}$, M. C. Mueller ${ }^{3}$, H. Jaeger ${ }^{6}$, R. Welte, \\ M. Baudewig ${ }^{7}$, R. Walli ${ }^{8}$, M. Stoll ${ }^{9}$ \\ ${ }^{1}$ MUC Research, Munich, Germany, \\ ${ }^{2}$ IBE, Ludwig-Maximilian University, Munich, Germany, \\ ${ }^{3}$ Department of Infectious Diseases, Medizinische Poliklinik, University Hospital of Munich, Munich, Downtown Campus; Germany, \\ ${ }^{4}$ Private Practice Dr. Becker/Dr. Pauli, Munich, Germany, \\ ${ }^{5}$ Private Practice Dr. Gorriahn, Munich, Germany, \\ ${ }^{6}$ MVZ Karlsplatz - HIV Research and Clinical Care Centre Munich, Munich, Germany, \\ ${ }^{7}$ GlaxoSmithKline, Munich, Germany, \\ ${ }^{8}$ ViiV Healthcare, Munich, Germany \\ ${ }^{9}$ Hannover Medical School, Dept. Clinical Immunology and Rheumatology, Hannover, Germany
}

\begin{abstract}
Objective: Avoiding abacavir in HIV-infected patients tested positive for HLA-B*5701 reduces the risk of abacavir hypersensitivity reaction (ABC-HSR). Our aim was to assess the costs of clinically suspected HSR and to estimate potential cost savings of implementing prospective HLA-B*5701-screening for HIVinfected patients initiating abacavir/lamivudine fixeddose combination (ABC/3TC FDC) compared to initiating respective treatment without screening.

Methods: Employing a decision tree model the expected HSR-related costs of screening vs. no screening were estimated from the societal and healthcare payer perspective (reference year 2007). A retrospective standardized assessment of all clinically suspected ABC-HSR cases without screening at 5 German HIVcentres was performed to measure resource consumption. In- and outpatient care, discarded $\mathrm{ABC} / 3 \mathrm{TC}$ FDC and concomitant medication were considered. Direct resource utilization was valued using German fees (EBM, G-DRGs). Indirect costs were measured with the human capital approach. Estimates for the HLA-B*5701-prevalence, HSR-incidence, and hospitalization rate were based on clinical trials and cohorts and it was assumed that screening reduces the incidence of clinically suspected ABC-HSR from $10 \%$ to $0.5 \%$.

Results: Thirty-two ABC-HSR cases were identified from 1998 to 2007. Mean direct and total costs per clinically suspected HSR case were $€ 1,362$ and $€ 2,235$, respectively. Hospital costs contributed $63.3 \%$ to direct costs. Potential cost savings when implementing genetic screening were estimated at $€ 44$ and $€ 127$ per screened patient, from a healthcare payer or societal perspective.

Conclusion: HLA-B*5701 screening prior to ABC/3TC FDC initiation prevents significant HSR-related costs per screened patient and is likely to lead to overall net savings.
\end{abstract}

Key words: HLA-B*5701, pharmacogenomics, abacavir

\section{INTRODUCTION}

To date, various host genetic factors are known to affect adverse drug reactions and therapeutic response to drugs [1, 2]. The implementation of genetic screening into clinical practice requires the evidence of improved safety or effectiveness of pharmaceutical care in prospective clinical trials. Due to limited financial resources in health care pharmacogenomic-based strategies also should aim to be cost-effective $[3,4]$. Besides improved clinical outcome, avoiding adverse drug effects may lead to cost savings which could offset the costs of genetic screening.

The application of pharmacogenomics in HIVtreatment is relatively recent. Genetic factors associated with drug metabolism, transport of drugs or immunogenetic factors have been described [5-11]. The human leukocyte antigen allele HLA-B*5701 is the first pharmacogenetic marker with proven clinical utility of genetic screening for improving patient safety in HIV-therapeutics. The presence of HLA-B*5701 is strongly associated with an increased risk for an abacavir-related hypersensitivity reaction (HSR) in Caucasian and also in non-Caucasian HIV-positive populations [12]. Abacavir is one of seven approved reverse transcriptase inhibitors used for combination therapy in HIV-positive patients.

The most treatment-limiting effect is an abacavir HSR occurring in 4-9\% of patients, mainly during the first six weeks of treatment [13-16]. In a large, doubleblinded, prospective two-arm clinical trial the incidence of clinically diagnosed abacavir HSR was reduced significantly when avoiding abacavir in patients tested positive for HLA-B*5701 [14]. Moreover, the risk of immunologically confirmed HSR has been completely eliminated.

Most guidelines for the treatment of HIV-infection have recently included the recommendation for prospective HLA-B*5701-screening prior to the initiation of abacavir [17-20]. Two studies assessed the costs attributed to an abacavir HSR and the potential 
cost savings that could be realized if prospective HLA-B*5701-screening is employed prior to the use of abacavir [21, 22]. These studies were carried out in the United States and in the United Kingdom. Thus, there is no data available for Germany yet.

The objective of our research project was to assess mean direct, indirect and total (direct + indirect) costs of clinically suspected HSR in Germany and to estimate potential cost savings of implementing prospective HLA-B*5701-screening for all HIV-positive patients initiating abacavir/lamivudine fixed-dose combination (ABC/3TC FDC) in Germany compared to initiating respective treatment without genetic screening.

\section{Methods}

A decision tree model was employed to simulate the expected costs of two alternative therapeutic strategies consisting of using ABC/3TC FDC as part of an antiretroviral treatment regimen either with prior prospective HLA-B*5701-screening or without genetic screening as previous standard of care. The model covered the time span until remission of abacavir-related HSR or up to six weeks of treatment with abacavir. Costs were estimated from the societal (direct + indirect costs) and health care payer (direct costs) perspective. Input parameters were derived from clinical trials or cohorts, specified German registries and reimbursement data of social and private health insurances as described below.

Direct costs included costs of HLA-B*5701-screening, physician services, concomitant medication for symptomatic treatment of HSR, diagnostic procedures, laboratory parameters, discarded ABC/3TC FDC and costs for inpatient care (according to diagnoses, procedures and length of stay). Indirect costs include costs for productivity loss due to temporary disability to work. 'MICE', a module for indirect cost estimation, was used for the calculation of indirect costs for productivity loss. The module has been developed at the University of Ulm, Germany [23].

To determine whether the results of the base case scenario are robust to plausible variations in input parameters we conducted one-way and multi-way (low cost scenario, high cost scenario) sensitivity analyses (see Table 1 for input parameters used in the base case, low and high cost scenarios). In the low cost scenario' the chosen input parameters reduce any existing cost savings potential of the screening strategy compared to the base case (lower HSR-related costs, lower efficiency and higher costs of the test). Input parameters in the 'high cost scenario' (higher HSR-related costs, higher efficiency and lower costs of the test) are in favour of any existing cost savings potential.

\section{5-Centre (5C) Study}

To measure the resource consumption related to an abacavir HSR, we performed a retrospective study of all clinically suspected abacavir HSRs documented at five German HIV-specialized centres. To get representative and valid data of resource utilization of outpa- tient and hospitalised cases, the participating centres consisted of three HIV outpatient care units (private practices) and two university hospital units specialized in $\mathrm{HIV} / \mathrm{AIDS}$.

A standardized questionnaire was used to assess the clinical presentation and resource utilization of clinically suspected abacavir HSRs. Inclusion criteria were a confirmed HIV-diagnosis, the use of abacavir without prior HLA-B*5701-screening and clinical symptoms which occurred during the first six weeks of abacavir treatment and which were consistent with an abacavir HSR [24-26].

\section{INPUT PARAMETERS}

Estimates for the incidence of clinically suspected abacavir HSR with and without prospective HLA$\mathrm{B} * 5701$-screening, hospitalization rate $(12 \%)$ and the prevalence of HLA-B*5701 in Germany were based on data from recent clinical trials and cohorts [14, 27, 28]. In PREDICT-1, the incidence of clinically suspected HSR $(7.8 \%)$ was higher than the prevalence of HLA-B*5701 (5.6\%) [14]. With a HLA-B*5701 prevalence of $7.3 \%$ in Germany, a ten percent rate of clinically suspected HSRs was expected for the base case scenario [27] (Table 1). On the basis of Australian data, it was assumed that withholding ABC/3TC FDC from HLA-B*5701 positive patients reduces the incidence of clinically suspected abacavir-related HSR from $10 \%$ to $0.5 \%$ [29].

Estimated private health insurance rates of HIV-infected patients were based on the German-wide situation [30] and on the analysis of more than thousand patients of a large German HIV-specialised private practice.

Average length of inpatient hospital stay and period of disability leave from work were derived from the 5C study. Distribution of age groups and gender among the HIV-positive population in Germany was chosen according to the federal annual health report of the Robert Koch Institute concerning incident HIV-infections in 2006 [31, 32]. Labour market data (rates of employed, unemployed and retired persons) were extracted from the statistical yearbook of the Federal Statistical Office [33].

\section{Resource Valuation}

Direct and indirect costs were calculated using 2007 as reference year. Resource utilization was valued using the Physicians' fee scale (EBM) of the social health insurance for outpatient treatment [34] and the per-case fees of the G-DRG system for inpatient treatment $[35,36]$. For patients with private health insurance, the outpatient fees were based on the doctors' fee ordinance for private health services [30, 37]. For inpatient patients with private health insurance, an extra charge for single rooms or chief physician attendance was included. Pharmacy prices [38] were used for calculating the costs for antiretroviral and other drugs. Currently, there is no official German price for HLA-B*5701screening. Instead, laboratories have different options to charge for HLA-B*5701-screening, resulting in a price range instead of a single price. We estimated the 
Table 1. Data and assumptions used for the base case analysis (using estimated average values) and for sensitivity analyses.

\begin{tabular}{|c|c|c|c|c|c|c|}
\hline \multirow{2}{*}{$\begin{array}{l}\text { Probabilities } \\
\text { Incidence of clinically } \\
\text { suspected HSR }\end{array}$} & \multicolumn{2}{|r|}{ Base case } & \multicolumn{2}{|r|}{ Low cost scenario } & \multicolumn{2}{|r|}{ High cost scenario } \\
\hline & $10.0 \%$ & $\begin{array}{c}\text { EPI-001 } \\
+ \text { PREDICT-1 } \\
{[14,27]}\end{array}$ & $7.8 \%$ & $\begin{array}{l}\text { PREDICT-1 } \\
\text { [14] }\end{array}$ & $12 \%$ & {$[28]$} \\
\hline Prevalence of HLA-B*5701 & $7.3 \%$ & $\begin{array}{l}\text { EPI-001 } \\
\quad[27]\end{array}$ & $5.6 \%$ & $\begin{array}{l}\text { PREDICT-1 } \\
{[14]}\end{array}$ & $9.5 \%$ & $\begin{array}{c}\text { EPI-001 } \\
\text { (Eastern Europe ethnicity) } \\
{[27]}\end{array}$ \\
\hline $\begin{array}{l}\text { Negative predictive value of } \\
\text { genetic HLA-B* } 5701 \text { test }\end{array}$ & $99.5 \%$ & assumption & $99 \%$ & assumption & $100 \%$ & $\begin{array}{c}\text { PREDICT-1 } \\
{[14]}\end{array}$ \\
\hline Hospitalization rate & $12.0 \%$ & unpublished data ${ }^{1}$ & $10 \%$ & unpublished data ${ }^{1}$ & $15 \%$ & unpublished data ${ }^{1}$ \\
\hline Private health insurance rates & $15 \%$ & $\begin{array}{l}5 \mathrm{C} \text { study } \\
+ \text { single centre } \\
\text { evaluation }\end{array}$ & $10 \%$ & $\begin{array}{l}\text { private health insurance } \\
\text { rate in total population } \\
\text { in Germany } \\
{[30]}\end{array}$ & $20 \%$ & $\begin{array}{c}\text { private health insurance rate in } \\
\text { HIV-infected population } \\
\text { in Germany } \\
{[30]}\end{array}$ \\
\hline $\begin{array}{l}\text { Percentage of antiretroviral } \\
\text { medication (ABC/3TC FDC) } \\
\text { being discarded }\end{array}$ & $53.7 \%$ & $5 \mathrm{C}$ study & $50 \%$ & assumption & $56.2 \%$ & $\begin{array}{l}\text { PREDICT-1 } \\
\text { [14] }\end{array}$ \\
\hline $\begin{array}{l}\text { Costs } \\
\text { Costs of HLA-B*5701- } \\
\text { screening }\end{array}$ & $€ 86$ & assumption & $€ 108$ & assumption & $€ 64$ & assumption \\
\hline $\begin{array}{l}\text { Costs of a monthly pack of } \\
\text { ABC/3TC }\end{array}$ & $€ 758$ & $\begin{array}{l}\text { Lauertaxe } \\
\qquad[38]\end{array}$ & NA & & NA & \\
\hline Concomitant medication & $€ 20$ & $5 \mathrm{C}$ study & $*$ & $*$ & * & \\
\hline Costs for outpatient care & $€ 73$ & 5C study & $*$ & $*$ & $*$ & \\
\hline $\begin{array}{l}\text { Hospital costs for cases } \\
\text { receiving inpatient care }\end{array}$ & $€ 6,904$ & 5C study & $€ 4,623$ & $\begin{array}{l}\text { 5C study: lump sum for } \\
\text { standard inpatient care } \\
\text { (DRG-Code S63B) }\end{array}$ & $€ 8,436$ & $\begin{array}{l}\text { 5C study: mean hospital costs in } \\
\text { 5-centre study when excluding } \\
\text { hospital stays of only one day }\end{array}$ \\
\hline $\begin{array}{l}\text { Extra charge for patients with } \\
\text { private health insurance }\end{array}$ & $€ 1,884$ & 5C study & NA & & NA & \\
\hline Indirect costs & $€ 873$ & $\begin{array}{l}\text { MICE module } \\
{[23,31-33]}\end{array}$ & $€ 0$ & & NA & \\
\hline
\end{tabular}

* Due to only minimal impact on cost outcomes, no sensitivity analyses performed; NA = not available

${ }^{1}$ GSK studies, data on file

costs associated with HLA-B*5701-screening on the basis of the different calculation schemes retrieved from 3 independent laboratories, taking into account the patient shares with private or statutory health insurance (Table 1).

Productivity loss was valued with age- and sex-specific labour costs and related to the length of hospital stay and/or period of disability leave from work (corrected for weekends). Labour costs included average annual gross income and employer's contributions and were related to the annual number of working days [39-41].

\section{RESULTS}

\section{C STUDY}

Thirty-two cases of clinically suspected abacavir HSR have been identified between January 1998 and May 2007, among them 29 Caucasians, two Asians and one African patient. Median age was 39.7 years (range 2571 years). Mean time on drug until the first reported symptoms was 10.8 days. After the occurrence of the first symptoms it took 9.7 days (mean) until abacavir was discontinued. Twenty patients suffered from symptoms of grades 1-2, and 12 patients suffered 
from symptoms of grades 3-4 [42], respectively. Twenty-two patients received outpatient care $(18 / 22$ with grade 1-2 symptoms); ten cases were admitted to hospital (8/10 with grade 3-4 symptoms). Mean length of hospital stay was 20.8 days (range $1-58$ days), mean number of days off due to sick leave (medical certificate) was 6.4 (excluding hospitalizations). On average, $53.7 \%$ of a monthly pack of $\mathrm{ABC} / 3 \mathrm{TC}$ FDC was discarded due to premature discontinuation.

\section{Base Case Analysis}

At a price of $€ 757.90$ for a monthly pack of $\mathrm{ABC} / 3 \mathrm{TC}$ FDC [38] the cost of discarding $53.7 \%$ of a monthly pack on average was $€ 407$ per case. Mean costs for other concomitant medication were estimated at $€ 20$. Mean costs for outpatient care amounted to $€ 73$ per case. Costs for inpatient care were a major cost driver in the $5 \mathrm{C}$ study and ranged from $€ 775$ for single day hospitalizations to $€ 16,865$ for a 58 -day hospital stay. Mean hospital costs for cases receiving inpatient care were estimated at $€ 6,904$ (median: $€ 5,800$ ). For patients with private health insurance, an extra charge of $€ 1,884$ for a single room or chief physician attendance was added.
With a $12 \%$ hospitalization rate and an estimated $15 \%$ private health insurance rate in HIV-infected patients in Germany, the mean hospital costs per clinically suspected HSR case were calculated at $€ 862$. Costs for in- and outpatient care, discarded $\mathrm{ABC} / 3 \mathrm{TC}$ FDC and concomitant medication added up to mean direct costs per clinically suspected HSR case of $€ 1,362$.

Indirect costs summed up to an average of $€ 873$ per case. Mean total costs per clinically suspected HSR were $€ 2,235$.

Assuming costs of HLA-B*5701-screening of $€ 86$ and that withholding ABC/3TC FDC from HLA$\mathrm{B} * 5701$ positive patients reduces the incidence of clinically suspected abacavir-related HSR from 10\% to $0.5 \%$, potential cost-savings when implementing genetic screening were estimated at $€ 44$ (direct costs) and $€ 127$ (total costs) per screened patient.

\section{SEnSitivity ANALYSES}

Taking the societal perspective, the most influential model parameter was the prevalence of HLA-B*5701 (€78 to €165) (Fig. 2). Total costs were moderately sensitive to variations in costs of HLA-B*5701screening (€105 to €149), in costs for inpatient care (€101 to $€ 145)$ and to variations in the hospitalization

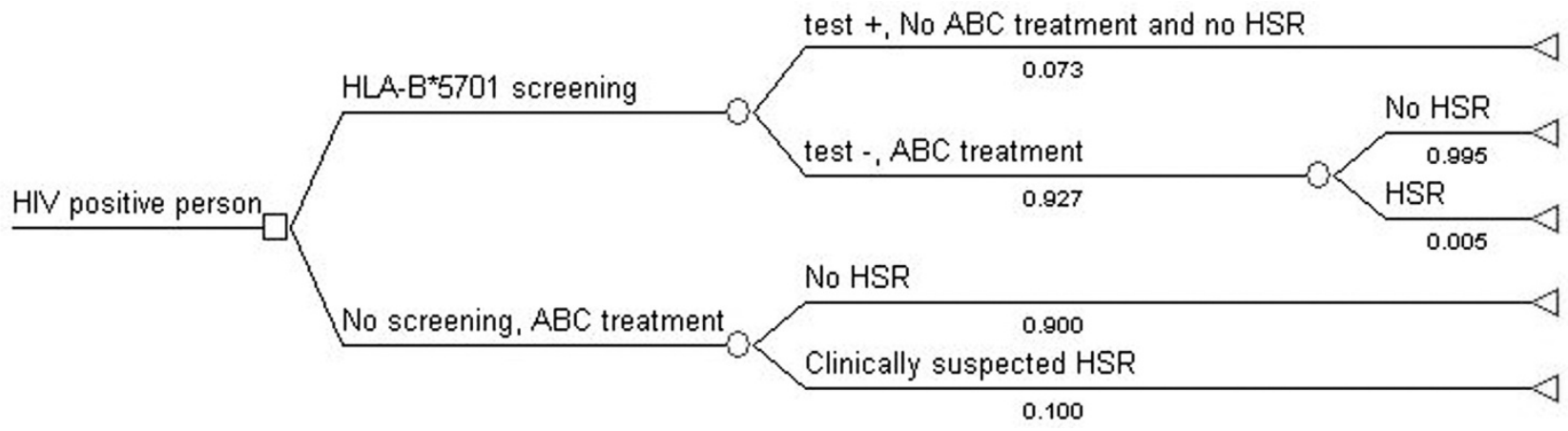

Fig. 1. Decision tree comparing two alternative strategies: Prospective HLA-B*5701-screening prior to using abacavir/lamivudine FDC as part of an antiretroviral treatment regimen versus initiation of abacavir/lamivudine FDC without genetic screening.

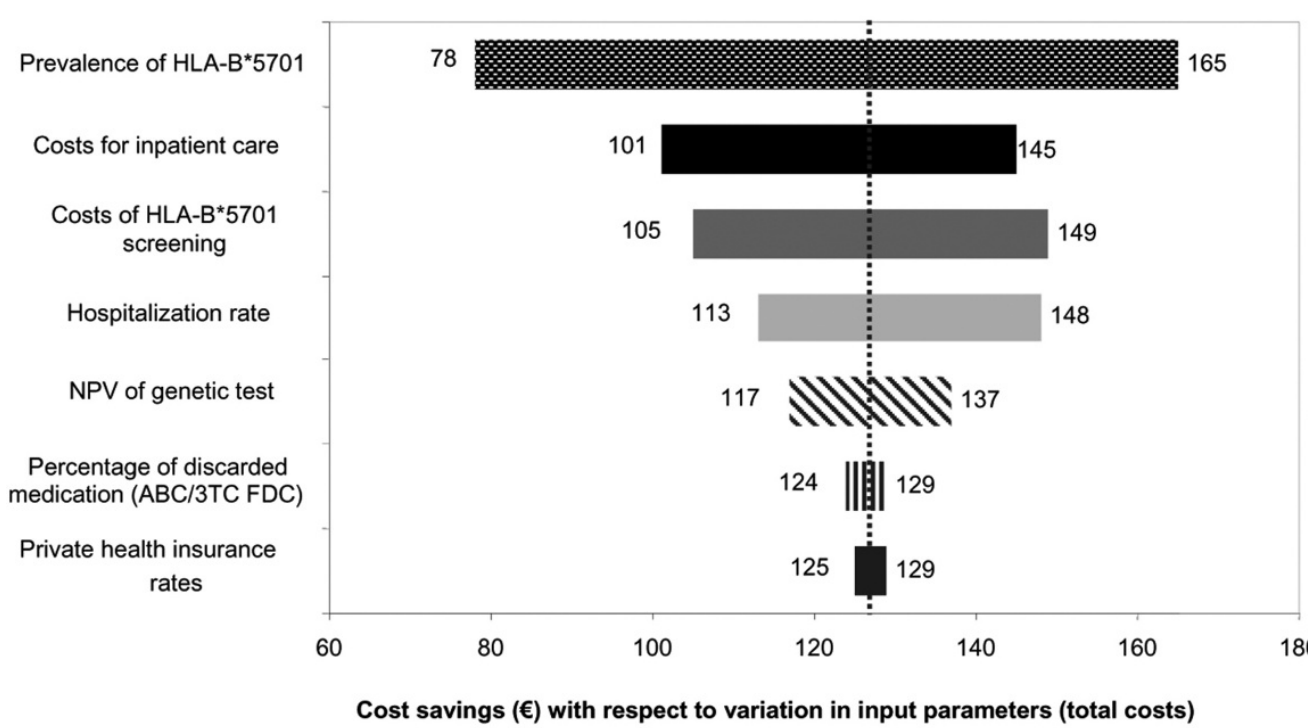

Fig. 2. One-way sensitivity analyses considering total costs (Tornado diagram). The vertical line depicts the base-case analysis with an expected value of $€ 127$. The input parameters for the low and high cost scenarios are shown in Table 1.

Abbreviations: $\mathrm{NPV}=$ negative predictive value; $\mathrm{ABC} / 3 \mathrm{TC}$ FDC $=$ abacavir/lamivudine fixed dose combination 
rate (€113 to €148). The results remained qualitatively robust (i.e. still rendering net savings) with respect to extreme value assumptions of the negative predictive value of genetic testing, the percentage of discarded antiretroviral medication, or the rate of private health insurance. When simultaneously employing extreme values of all parameters (low and high cost scenarios), total cost savings ranged from $€ 16$ (low cost scenario) to $€ 254$ (high cost scenario). By taking the healthcare payers' perspective and thus considering direct costs only, results of the sensitivity analysis remained similar with respect to the sensitivity of the model parameters (Figure not shown). Results ranged from additional costs of $€ 43$ (low cost scenario) to cost savings of $€ 152$ (high cost scenario).

\section{Discussion}

Treatment guidelines have implemented HLAB*5701-screening prior to using abacavir as part of antiretroviral treatment regimens [17-20]. These recommendations are based on clinical studies and cohorts showing a marked reduction in clinically suspected HSRs when avoiding abacavir in patients screened positive for HLA-B*5701 [14]. Our study addresses the economic issues related to the implementation of HLA-B*5701-screening in Germany. Using a decision tree model we compared direct and indirect HSR-related costs of either HLA-B*5701-screening prior to $\mathrm{ABC} / 3 \mathrm{TC}$ FDC initiation or previous standard of care treatment without prospective genetic screening. The evaluation of direct costs was based on a small retrospective cohort of $32 \mathrm{HIV}$-patients with clinically suspected abacavir-related HSR. Since one inclusion criterion was that HSR did not occur later than May 2007, the genetic information on HLA-B*5701 carriage was not available for these patients. Patients were included based only on symptoms, the investigator's judgment and the temporal context with starting treatment with abacavir, but irrespective of HLA-B*5701 carriage - thus representing unbiased clinical diagnoses of abacavir-related HSRs.

Cost evaluation of clinically suspected HSR cases was limited by the relatively small sample size of only 32 cases. Resource utilization for outpatient care may vary in different settings and depends on symptoms. However, due to its relatively low contribution to total costs, variations do not have any strong influence on estimated potential cost savings. The costs for discarded antiretroviral medication when prematurely discontinuing $\mathrm{ABC} / 3 \mathrm{TC}$ FDC were a major cost driver. Like in PREDICT-1 [14] more than 50\% of medication prescribed for one month was discarded in the $5 \mathrm{C}$ study. We did not include the costs for replacing $\mathrm{ABC} / 3 \mathrm{TC}$ by another drug combination.

Our model covered the time span until remission of abacavir-related HSR or up to six weeks of treatment with abacavir. The goal of this analysis was to compare short-term outcomes of the two ACB/3TCbased strategies and to show the cost savings potential of genetic screening prior to using $\mathrm{ABC} / 3 \mathrm{TC}$. The goal was not to model long-term outcomes including different treatment regimens and treatment changes due to side effects or virological failure. This has been done by Schackman and colleagues who published a computer-based state transition model of HIV-disease in the United States to project long-term outcomes of first-line ABC/3TC- or tenofovir/emtricitabine (TDF/FTC)-containing regimens and respective expenses [22]. In this model, prospective genetic screening for all patients prior to initiating HAART and treatment initiation with an $\mathrm{ABC} / 3 \mathrm{TC}$-based regimen for those tested HLA-B*5701 negative was preferred to initiating all patients on a TDF/FTC-based regimen as long as the costs for $\mathrm{ABC} / 3 \mathrm{TC}$ were lower than those for TDF/FTC (at least 2 US \$) and provided that $\mathrm{ABC} / 3 \mathrm{TC}$-based therapy had equivalent efficacy to TDF/FTC therapy ( $<1 \%$ difference for 48 -week virological responses rate defined as $<400$ copies $/ \mathrm{ml}$ ).

In contrast to Schackman's work, the goal of our analysis was different, as is the conclusion: We modelled a situation in which the physician has already decided, for whatever reasons, to treat a patient with $\mathrm{ABC} / 3 \mathrm{TC}$. Identifying patients at risk of $\mathrm{ABC}-\mathrm{HSR}$ using prospective genetic screening and withholding ABC/3TC treatment from those patients turned out to have cost-saving potential compared to treatment initiation without genetic screening.

The prevalence of HLA-B*5701 varies in different ethnic groups of a population. In our model, the base case assumption for the situation in Germany was based on a German epidemiological study (EPI-001) in HIVpatients [27]. For sensitivity analysis we simulated the European and Australian populations of the PREDICT1 study with a lower HLA-B*5701-prevalence than in the German survey (5.6\% versus $7.1 \%$ ) [14]; the corresponding cost savings decreased from $€ 127$ to $€ 78$.

Since in PREDICT-1 approximately $0.5 \%$ of patients negative for HLA-B*5701 had a clinically suspected HSR, we accounted for this proportion in the base case analysis. Negative predictive values of genetic screening between $99 \%$ and 100\% were used in the sensitivity analysis resulting in cost savings between $€ 117$ and $€ 137$.

HLA-B*5701 screening prior to ABC/3TC FDC initiation prevents significant HSR-related costs per screened patient and is likely to lead to overall net savings. Irrespective of economic considerations, there is a clear medical benefit of prospective HLA-B*5701screening prior to abacavir use. The implementation of HLA-B*5701-screening will be an important milestone for using genetic testing to improve drug safety and bringing individualized medicine to clinical practice.

Acknowledgement: This study was sponsored by GlaxoSmith Kline, Germany.

Conflict of interests: Robert Welte and Monika Baudewig are employees of GlaxoSmithKline, Germany. Ravi Walli is an employee of ViiV Healthcare, Germany.

\section{REFERENCES}

1. Lee W, Lockhart AC, Kim RB, Rothenberg ML. Cancer pharmacogenomics: powerful tools in cancer chemotherapy and drug development. Oncologist 2005; 10: 104-111.

2. Eichelbaum M, Ingelman-Sundberg M, Evans WE. Pharmacogenomics and individualized drug therapy. Annu Rev Med 2006; 57: 119-137. 
3. Veenstra DL, Higashi MK, Phillips KA. Assessing the cost-effectiveness of pharmacogenomics. AAPS PharmSci 2000; 2: E29.

4. Flowers CR, Veenstra D. The role of cost-effectiveness analysis in the era of pharmacogenomics. Pharmacoeconomics 2004; 22: 481-493.

5. Owen A, Pirmohamed M, Khoo SH, Back DJ. Pharmacogenetics of HIV therapy. Pharmacogenet Genomics 2006; 16: 693-703.

6. Ritchie MD, Haas DW, Motsinger AA, et al. Drug transporter and metabolizing enzyme gene variants and nonnucleoside reverse-transcriptase inhibitor hepatotoxicity. Clin Infect Dis 2006; 43: 779-782.

7. Rotger M, Colombo S, Furrer H, et al. Influence of CYP2B6 polymorphism on plasma and intracellular concentrations and toxicity of efavirenz and nevirapine in HIV-infected patients. Pharmacogenet Genomics 2005; 15: 1-5.

8. Saitoh A, Sarles E, Capparelli E, et al. CYP2B6 genetic variants are associated with nevirapine pharmacokinetics and clinical response in HIV-1-infected children. AIDS 2007; 21: 2191-2199.

9. Hetherington S, Hughes AR, Mosteller M, et al. Genetic variations in HLA-B region and hypersensitivity reactions to abacavir. Lancet 2002; 359: 1121-1122.

10. Mallal S, Nolan D, Witt C, et al. Association between presence of HLA-B*5701, HLA-DR7, and HLA-DQ3 and hypersensitivity to HIV-1 reverse-transcriptase inhibitor abacavir. Lancet 2002; 359: 727-732.

11. Martin AM, Nolan D, James I, et al. Predisposition to nevirapine hypersensitivity associated with HLADRB1*0101 and abrogated by low CD4 T-cell counts. AIDS 2005; 19: 97-99.

12. Saag M, Balu R, Brachman P, et al. High sensitivity of HLA-B*5701 in whites and blacks in immunologicallyconfirmed cases of abacavir hypersensitivity. 4th International AIDS Society Conference on HIV Pathogenesis, Treatment and Prevention. 22-25 July 2007, Sidney, Australia. Abstract WEAB305

13. Hetherington S, McGuirk S, Powell G, et al. Hypersensitivity reactions during therapy with the nucleoside reverse transcriptase inhibitor abacavir. Clin Ther 2001; 23: 1603 1614.

14. Mallal S, Phillips E, Carosi G, et al. HLA-B*5701 screening for hypersensitivity to abacavir. N Engl J Med 2008; 358: 568-579.

15. Moyle GJ, DeJesus E, Cahn P, et al. Abacavir once or twice daily combined with once-daily lamivudine and efavirenz for the treatment of antiretroviral-naive HIVinfected adults: results of the Ziagen Once Daily in Antiretroviral Combination Study. J Acquir Immune Defic Syndr 2005; 38: 417-425.

16. Symonds W, Cutrell A, Edwards M, et al. Risk factor analysis of hypersensitivity reactions to abacavir. Clin Ther 2002; 24: 565-573.

17. Guidelines for the Use of Antiretroviral Agents in HIV-1 Infected Adults and Adolescents; November 2008. DHHS Panel on Antiretroviral Guidelines for Adults and Adolescents [cited on 19 February 2009]. Available from http://aidsinfo.nih.gov/contentfiles/AdultandAdoles centGL.pdf

18. EACS Guidelines for the Clinical Management and Treatment of HIV-infected Adults in Europe, October 2008: Version 4. EACS [cited on 19 February 2009]. Available from http://www.eacs.eu/Guidelines_Livret/index.htm

19. Leitlinien für Diagnostik und Therapie der HIV-Infektion. DAIG (Deutsche AIDS-Gesellschaft) \& ÖAG (Österreichische AIDS-Gesellschaft) [cited on 13 June 2008]. Available from http://www.daignet.de/site-content/ hiv-therapie/leitlinien-1

20. BfArM Risikoinformationen Abacavir. BfArM (Bundesinstitut für Arzneimittel und Medizinprodukte) [cited on 13
June 2008]. Available from http://www.bfarm.de/ cln_029/nn_421158/DE/Pharmakovigilanz/risikoinfo/ abacavir.html_nnn=true

21. Hughes DA, Vilar FJ, Ward CC, Alfirevic A, Park BK, Pirmohamed M. Cost-effectiveness analysis of HLA $\mathrm{B} * 5701$ genotyping in preventing abacavir hypersensitivity. Pharmacogenetics 2004; 14: 335-342.

22. Schackman BR, Scott CA, Walensky RP, Losina E, Freedberg KA, Sax PE. The cost-effectiveness of HLA-B*5701 genetic screening to guide initial antiretroviral therapy for HIV. AIDS 2008; 22: 2025-2033.

23. Welte R, Koenig H, Jager J, Leidl R. Assessment of indirect costs of injecting drug use: which methods should be employed? In Hepatitis $\mathrm{C}$ and injecting drug use: impact, costs and policy options. European Monitoring Centre for Drugs and Drug Addicition Monographs 7. Edited by J Jager, W Limburg, M Kretzmar, M Poostma, L Wiessing. Luxembourg: Office for Official Publications of the European Communities; 2004. pp. 249-267.

24. Clay PG. The abacavir hypersensitivity reaction: a review. Clin Ther 2002; 24: 1502-1514.

25. Cutrell AG, Hernandez JE, Fleming JW, et al. Updated clinical risk factor analysis of suspected hypersensitivity reactions to abacavir. Ann Pharmacother 2004; 38: 2171 2172.

26. Kivexa Product Information Kivexa-H-C-581-II-18. EMEA [cited on 29 February 2008]. Available from http://www.emea.europa.eu/humandocs/Humans/EPA $\mathrm{R} /$ kivexa/kivexa.htm

27. Esser S, van Lunzen J, Baudewig M, et al. Phenotype Frequency of HLA-B*5701 in HIV-Infected Patients in Germany. 9 Kongress für Infektiologie und Tropenmedizin. 27 February - 1 March 2008, Innsbruck, Switzerland. Abstract P219

28. Zucman D, Truchis P, Majerholc C, Stegman S, CaillatZucman S. Prospective screening for human leukocyte antigen-B*5701 avoids abacavir hypersensitivity reaction in the ethnically mixed French HIV population. J Acquir Immune Defic Syndr 2007; 45: 1-3.

29. Rauch A, Nolan D, Martin A, McKinnon E, Almeida C, Mallal S. Prospective genetic screening decreases the incidence of abacavir hypersensitivity reactions in the Western Australian HIV cohort study. Clin Infect Dis 2006; 43: 99-102.

30. Zahlenbericht der privaten Krankenversicherung 2006/ 2007. Verband der privaten Krankenversicherung e.V. [cited on 11 December 2007]. Available from http://www.pkv.de/zahlen/zahlenbericht_2006_2007.pdf

31. Gesundheitsberichterstattung des Bundes: Themenheft 31: HIV und AIDS. Robert Koch-Institut [cited on 17 November 2007]. Available from http://www.rki.de/cln_049/nn_199850/DE/Content/ GBE/Gesundheitsberichterstattung/GBEDownloadsT/ hiv__aids,templateId=raw,property=publicationFile.pdf/ hiv_aids.pdf

32. Gesundheit in Deutschland. Gesundheitsberichterstattung des Bundes. Robert Koch-Institut [cited on $17 \mathrm{Sep}-$ tember 2007]. Available from

http://www.gbe-bund.de/gbe10/owards.prc_show _pdf?p_id=9965\&p_sprache=D\&p_uid=gast\&p_aid=19 790274\&p_lfd_nr=1

33. Statistisches Bundesamt. Statistisches Jahrbuch für die Bundesrepublik Deutschland 2006. Wiesbaden: Statistisches Bundesamt; 2006.

34. EBM, Einheitlicher Bewertungsmaßstab, 4/2007. Kassenärztliche Bundesvereinigung [cited on 26 September 2007]. Available from http://www.kbv.de/ebm2000plus/EBMGesamt.htm

35. DRG WebGrouper, 2007. DRG-Research-Group [cited on 1 July 2007]. Available from http://drg.uni-muenster. $\mathrm{de} / \mathrm{de} /$ webgroup/m.webgroup.php? $\mathrm{menu}=6$ 
36. Übersicht über die für 2007 gültigen Landesbasisfallwerte in den einzelnen Bundesländern. AOK-Bundesverband [cited on 8 June 2007]. Available from

http://www.aok-gesundheitspartner.de/imperia/md/ content/gesundheitspartner/bund/krankenhaus/ budgetverhandlungen/lbfw_2007_uebersicht.pdf

37. Gebührenordnung für Ärzte (GOÄ). Gutermann Publisher Ltd [cited on 13 June 2008]. Available from http://www.e-bis.de/goae/defaultFrame.htm

38. Lauer Taxe 2007. LAUER-FISCHER GmbH [cited on 23 September 2007]. Available from http://www.lauer-fischer.de/LF/Seiten/Produkte/ Online-Dienste/Lauer-Taxe\%20online.aspx;

39. Statistisches Bundesamt. Löhne und Gehälter Oktober 2006, Fachserie 16 Reihe 2.2. Wiesbaden: Statistisches Bundesamt; 2007.

40. Sozialversicherungspflichtig Beschäftigte nach Altersgruppen in der Bundesrepublik Deutschland. Bundesagentur für Arbeit [cited on 13 June 2008]. Available from

http://www.pub.arbeitsamt.de/hst/services/statistik/ aktuell/iiia6/sozbe/zr_svb_alterd.xls
41. Daten zur kurzfristigen Entwicklung von Wirtschaft und Arbeitsmarkt. Ausgabe Nr. 12 / 2006. Institut für Arbeitsmarkt und Berufsforschung der Bundesagentur für Arbeit (IAB). [cited on 13 June 2008]. Available from http://doku.iab.de/werkber/2006/wb_arbeitszeit.pdf

42. The Division of AIDS Table for Grading the Severity of Adult and Pediatric Adverse Events, Version 1.0, Dec 2004. DAIDS (Division of Acquired Immunodeficiency Syndrome) [cited on 13 June 2008]. Available from http://rcc.tech-res.com/eae.htm

Received: July 19, 2009 / Accepted: March 4, 2010

Address for correspondence:

Eva Wolf, Dipl. Phys., M.P.H.

MUC Research GmbH

Karlsplatz 8

80335 Munich

Germany

Tel: $\quad+49895587030$

Fax: +49895503941

E-mail: ewo@mucresearch.de 